\title{
Dual-Band Patch Antenna Fed by Meandering Probe for Low Cross-Polarization
}

\author{
Xiao-Lan Zhao and Quan Wei Lin \\ School of Electronic and Information Engineering, South China University of Technology, Guangzhou 510640, China
}

Correspondence should be addressed to Quan Wei Lin; quanweilin1008@gmail.com

Received 6 November 2015; Accepted 14 February 2016

Academic Editor: Xiulong Bao

Copyright (C) 2016 X.-L. Zhao and Q. W. Lin. This is an open access article distributed under the Creative Commons Attribution License, which permits unrestricted use, distribution, and reproduction in any medium, provided the original work is properly cited.

\begin{abstract}
This paper presents a dual-band patch antenna loaded with face-to-face U-shaped slots fed by a substrate-integrated meandering probe (SIM-probe). With the presence of U-shaped slots, two current paths are formed, which leads to the resonance modes at 2.4 and $3.65 \mathrm{GHz}$ on the patch. The SIM-probe suppresses the unwanted cross-polarization radiations by providing out-of-phase vertical currents from vertical metallic vias. To verify our work, a prototype was fabricated and tested. The proposed antenna achieves the impedance bandwidths of $9.4 \%$ and $9 \%$ from the frequency range of $2.34-2.57 \mathrm{GHz}$ and $3.5-3.83 \mathrm{GHz}$ (for the reflection coefficient $\leq-10 \mathrm{~dB}$ ) and obtains average gains of $5.8 \mathrm{dBi}$ and $6.8 \mathrm{dBi}$ at both bands. The cross-polarization level is below $-20 \mathrm{~dB}$. Measured results agree well with the simulation.
\end{abstract}

\section{Introduction}

With the development of the wireless communication, the wireless networks should be compatible with dual-band and dual-mode standards such as $2.4 \mathrm{GHz}$ WLAN band and 3.5 GHz WiMAX band. Accordingly, the dual-band antennas are required in the modern wireless systems [1-4].

Patch antennas with dual-band operation are attractive due to the inherent advantage of low profile, broadside radiation, and easy fabrication [5-7]. In the past, a lot of techniques have been proposed. An effective design is to add a stacked patch to the driven patch [7] which generates double resonances. In addition, the patch antenna with a U-shaped slot can also realize dual-band operation [8] but it may suffer from the inherent weakness of narrow impedance bandwidth. Although the method of using an L-shaped probe feed can enhance the impedance bandwidth for the dual-band patch antenna [9]; this design may cause an asymmetric radiation pattern and a high cross-polarization radiation.

The high cross-polarization is a problematic issue in a lot of dual-band patch antennas, especially at upper bands [79]. To solve this problem, differential feed [10] is proposed to suppress the cross-polarization radiation. However, if the isolation between two differential ports is low, it may lead to lower gain and thus complex feeding networks should be designed to enhance the isolation. The meandering probe [11] is one of effective techniques for suppressing the high cross-polarization radiation of the patch antenna. However, the reported work in [11] only demonstrates low crosspolarization levels only in one frequency band. Besides, the air loaded meandering probe increases the fabrication tolerance.

In this paper, a patch antenna fed by the substrateintegrated meandering probe (SIM-probe) is proposed to achieve dual-band low cross-polarization performance. The dual-band operation is realized by the patch loaded with two U-shaped slots which provide the patch with two broadside resonances at the frequencies of 2.45 and $3.65 \mathrm{GHz}$. Moreover, the dual-band patch antenna achieves low cross-polarization levels within the two bands due to the symmetrical current distribution on the patch and the meandering probe. The characteristics of L-probe fed dual-band patch antenna are also presented for demonstrating the advantage of the proposed M-probe.

\section{Antenna Geometry}

Figures 1 and 2 show the geometry of dual-band patch antenna. The antenna consists of four pieces of PCB substrate (Substrates 1-4 with thickness $h$ ). The ground plane is printed 


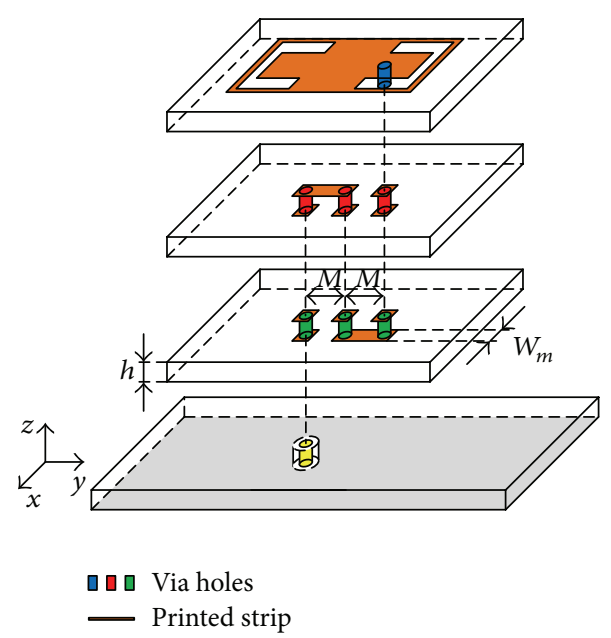

Figure 1: 3D view of the proposed substrate-integrated M-probe fed dual-band patch antenna.

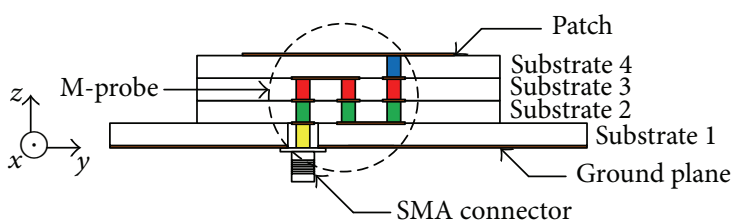

(a)

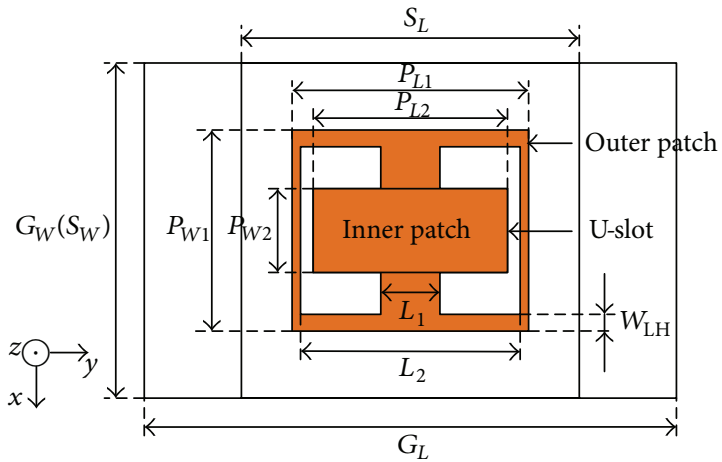

(b)

Figure 2: Geometry of substrate-integrated M-probe fed dual-band patch antenna. (a) Side view. (b) Top view.

on the bottom layer of Substrate 1 and the patch is printed on the top layer of Substrate 4 . Substrate 1 has the same size as the ground plane with $G_{L} \times G_{W}$, while Substrates 2-3 are in square shape with the size of $S_{L} \times S_{W}$. The patch loaded with two U-slots which separate it into two parts as the inner patch and the outer patch as shown in Figure 2(b). The inner patch with the length $P_{L 2}$ and the width $P_{W 2}$ is located at the center. The width and length of the outer patch are $P_{W 1}$ and $P_{L 1}$, respectively. The parameters of $W_{\mathrm{LH}}, L_{1}$, and $L_{2}$ are presented to define the size and position of the face-to-face U-slots. The patch is fed by the meandering probe which is integrated in the substrate $\mathrm{F} 4 \mathrm{~B}$ with a dielectric constant of 2.65 and a layered thickness of $3 \mathrm{~mm}$ as shown in Figure 2(a). The meandering probe is formed by the folded strip with two horizontal arms and three vertical portions. The horizontal arms of the meandering strip are formed by the printed strips on Substrates 2 and 3 and the vertical portions are realized by the metallic vertical-plated-through holes with a diameter of $1 \mathrm{~mm}$.

A $50 \Omega$ SMA connector is located underneath the ground plane through the dug hole with a diameter of $2.3 \mathrm{~mm}$. The detailed values of the parameters are tabulated in Table 1.
TABLE 1: Values of key parameters.

\begin{tabular}{lccccccc}
\hline Parameters & $G_{L}$ & $G_{W}$ & $S_{L}$ & $P_{L 1}$ & $P_{W 1}$ & $P_{L 2}$ & $P_{W 2}$ \\
Values/mm & 63 & 40 & 40 & 27 & 22 & 24 & 10 \\
Parameters & $W_{\mathrm{LH}}$ & $L_{1}$ & $L_{2}$ & $M$ & $W_{m}$ & $h$ & \\
Values/mm & 1 & 7 & 26 & 5.5 & 2.4 & 3 & \\
\hline
\end{tabular}

\section{Dual-Band Operation}

The current distributions of the proposed antenna are illustrated in Figure 3. As shown in Figure 3(a), the current distribution at $2.45 \mathrm{GHz}$ is concentrated at the edge of the outer patch with the electrical length of half guided wavelength. The current vectors on the edges of the patch (along the $y$ axis) are in-phase, which contributes to the copolarization radiation. At $3.65 \mathrm{GHz}$, the radiation is generated by the inner patch where the current distribution is concentrated as shown in Figure 3(b). Figure 4 shows the electric field distributions of the proposed antenna at $2.45 \mathrm{GHz}$ and $3.65 \mathrm{GHz}$. It is demonstrated that the radiation of the proposed antenna at $2.45 \mathrm{GHz}$ is from the edges of the outer patch as shown 


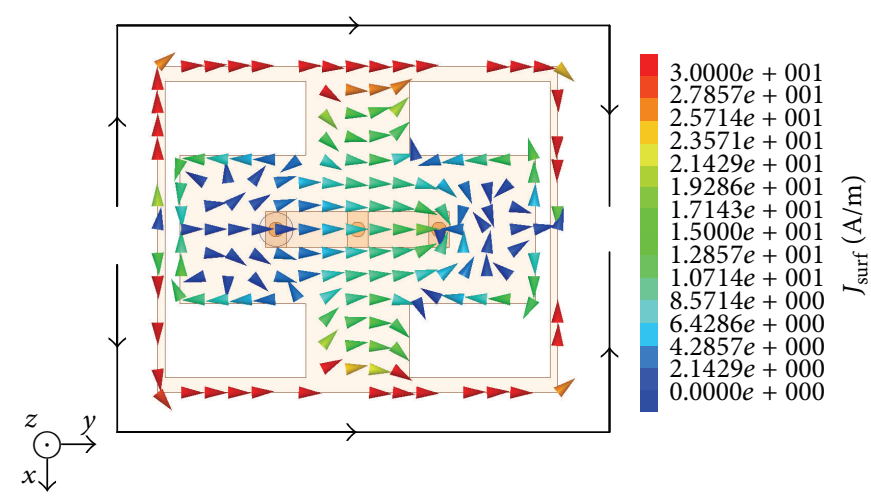

(a)

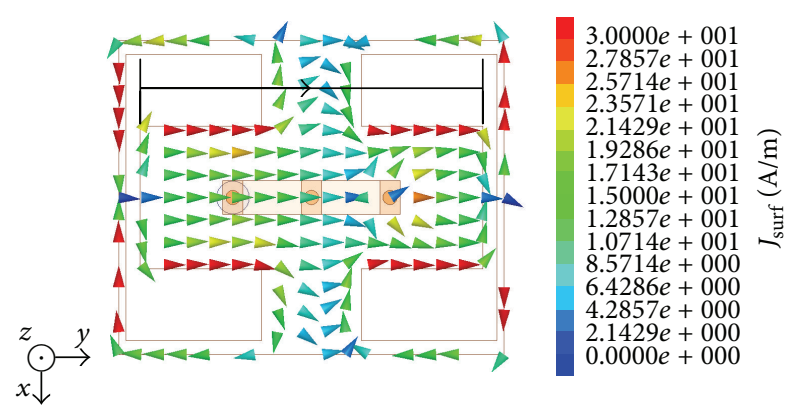

(b)

FIGURE 3: Current distributions of the proposed antenna at (a) $2.45 \mathrm{GHz}$ and (b) $3.65 \mathrm{GHz}$.

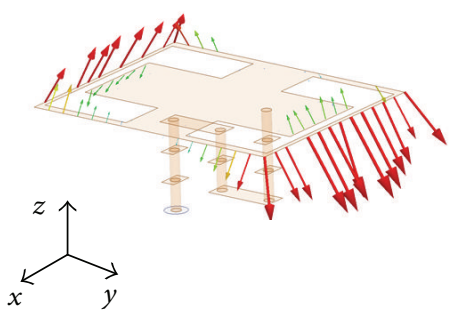

(a)

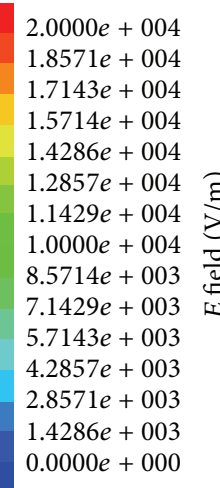

$0.0000 e+000$

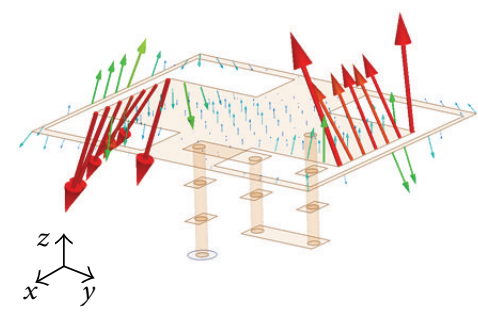

(b)

FIGURE 4: Electric field distributions on the patch of the proposed antenna at (a) $2.45 \mathrm{GHz}$ and (b) $3.65 \mathrm{GHz}$.

in Figure 4(a). For the upper frequency of $3.65 \mathrm{GHz}$, the radiation is mainly from the edge of the inner patch as shown in Figure 4(b).

To further verify the working mechanism of the antenna, the effect of parameters $P_{L 1}$ and $P_{L 2}$ on the antenna's reflection coefficient is studied. Figure 5 presents the simulated reflection coefficients of the proposed antenna with different $P_{L 1}$. It is observed that the first resonant frequency shifts from 2.38 to $2.6 \mathrm{GHz}$ as $P_{L 1}$ varied from 26.5 to $27.5 \mathrm{~mm}$ while keeping other parameters fixed. This indicates that the length of the patch is related to the resonance of the lower band which is presented in Figure 3(a). Similarly, the effect of different inner patch lengths $\left(P_{L 2}\right)$ on the simulated reflection coefficients is also taken out. As shown in Figure 6, the second resonance shifts to lower frequencies as $P_{L 2}$ increases. It is found that the optimized length of the inner patch should be half guided length at $3.65 \mathrm{GHz}$ approximately. On the other hand, the matching at lower band changes as $P_{L 2}$ increases. This is due to the electric coupling between the inner and the outer parts which becomes stronger as $P_{L 2}$ increased and this can improve the capacitance of the total circuit, which may influence the matching of the lower band as shown in Figure 4(b).
The dual-band operation is due to two current paths, while the cross-polarization level is mainly related to the substrate-integrated meandering probe. The effect of the horizontal strip length $M$ on the radiation patterns in both bands is presented in Figures 7 and 8 . As $M$ increases, the cross-polarization levels of the proposed antenna at $2.45 \mathrm{GHz}$ decrease. On the other hand, as $M$ increases, the crosspolarization levels at $3.65 \mathrm{GHz}$ increase. The results indicate that the length of the meandering probe should be optimized to obtain low cross-polarization levels within both bands.

\section{Results and Discussion}

To demonstrate the idea for SIM-probe fed dual-band patch antenna loaded by two U-shaped slots, the proposed antenna was fabricated and measured. All of the simulated results were carried out by the Ansoft HFSS. The impedance and radiation pattern measurement were carried out by an Agilent Technologies E5071C network analyzer and the Satimo StarLab measurement system, respectively.

Figure 9 shows the simulated reflection coefficients and gains. It is seen that the measured impedance bandwidth is 9.4\% (2.34-2.57 GHz) and 9\% (3.5-3.83 GHz), which covers 


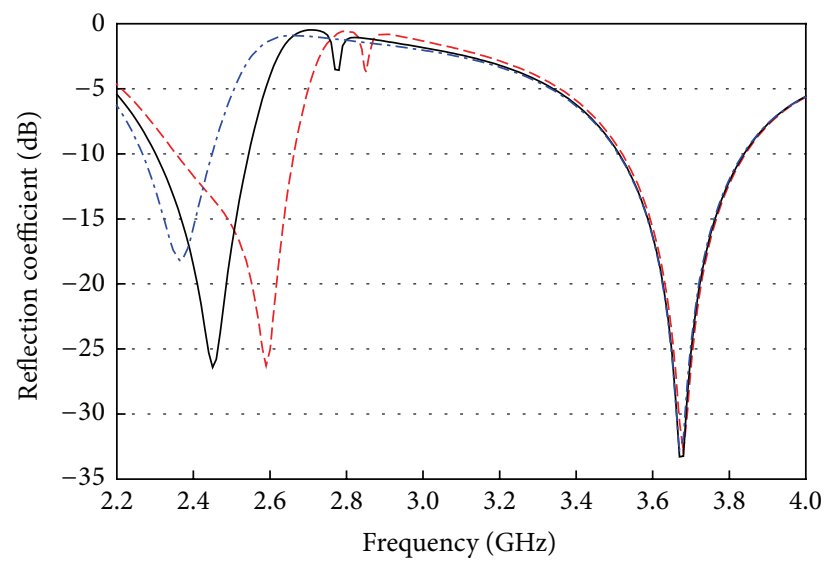

$$
\begin{aligned}
& --P_{L 1}=26.5 \mathrm{~mm} \quad \cdots-P_{L 1}=27.5 \mathrm{~mm} \\
& -P_{L 1}=27 \mathrm{~mm}
\end{aligned}
$$

FIGURE 5: Simulated reflection coefficients for different $P_{L 1}$.

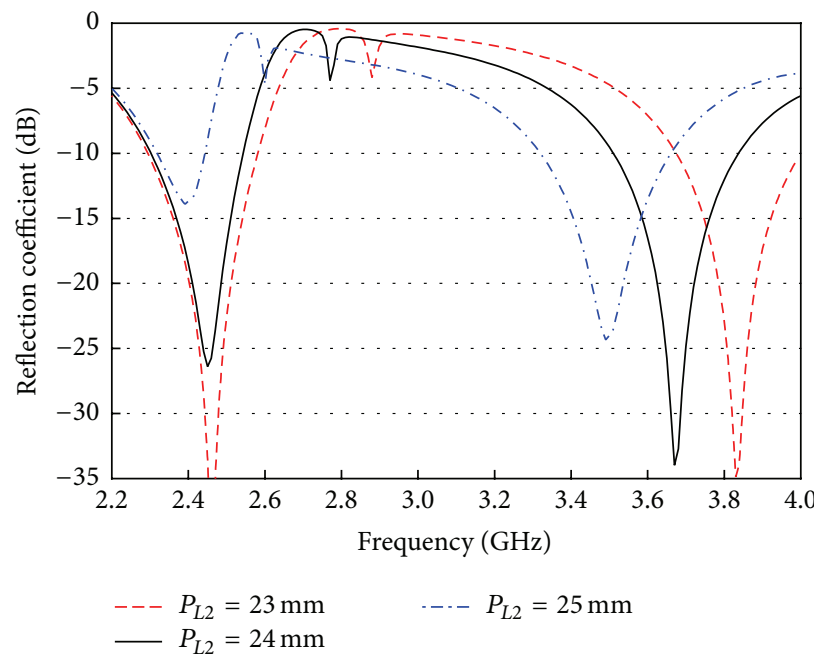

Figure 6: Simulated reflection coefficients for different $P_{L 2}$.

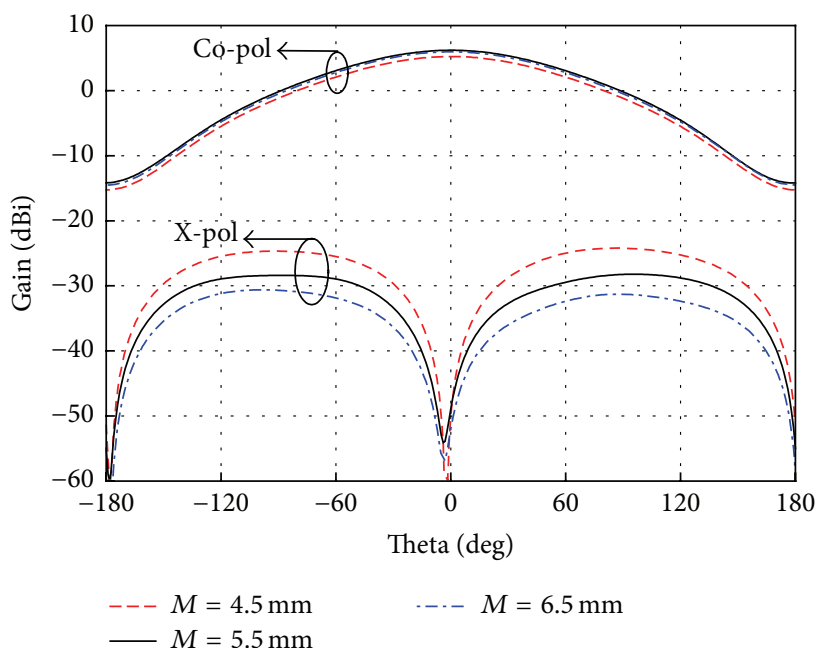

Figure 7: Simulated radiation patterns in $H$-plane at $2.45 \mathrm{GHz}$ for different $M$. 


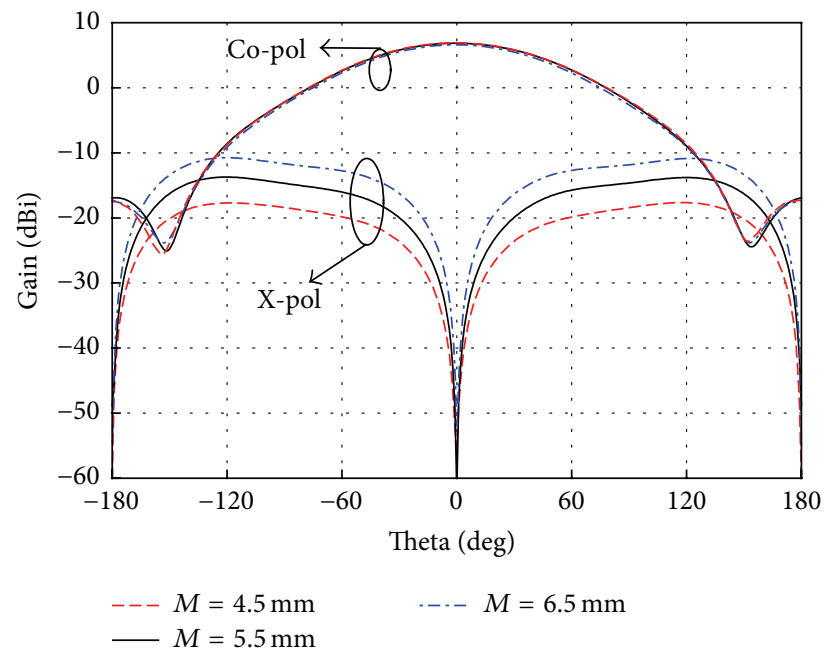

FIGURE 8: Simulated radiation patterns in $H$-plane at $3.65 \mathrm{GHz}$ for different $M$.

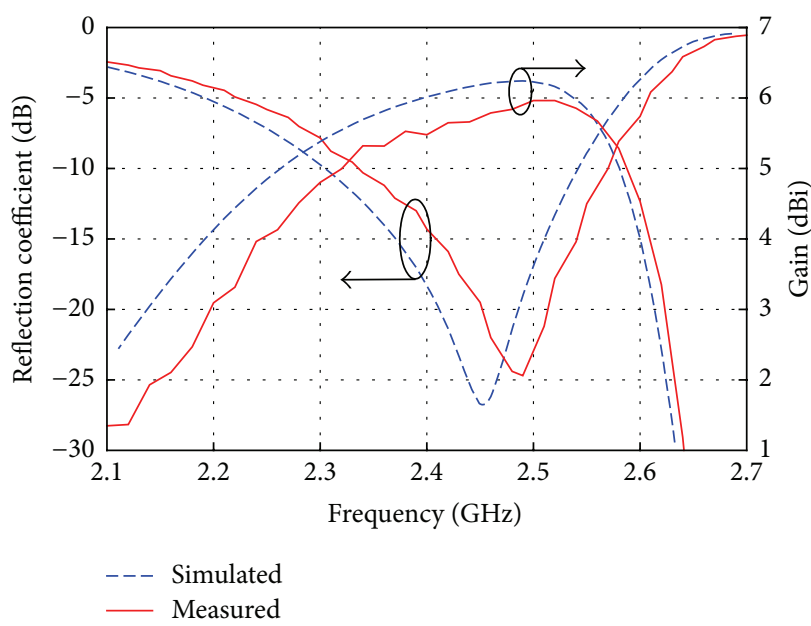

(a)

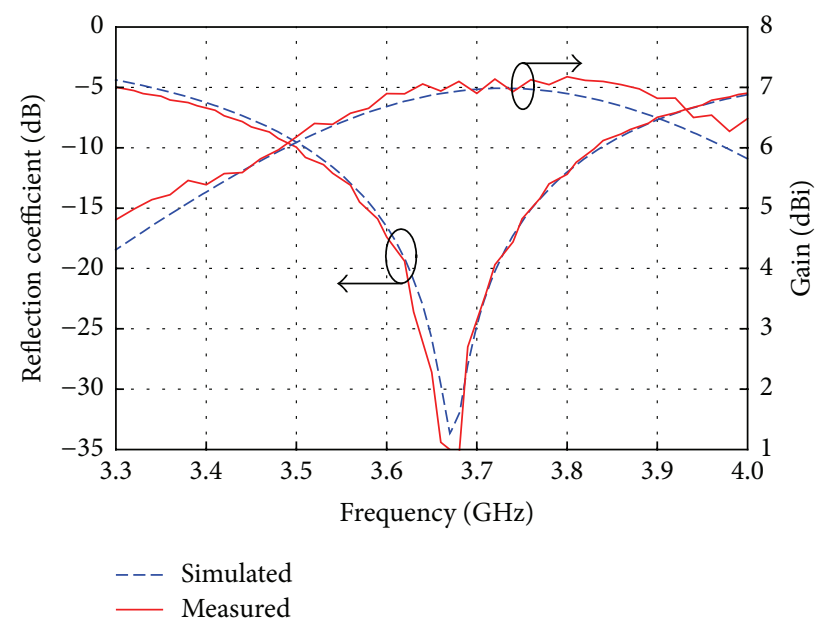

(b)

FIGURE 9: Simulated and measured reflection coefficients and gains for the proposed patch antenna at (a) $2.45 \mathrm{GHz}$ band and (b) $3.5 \mathrm{GHz}$ band.

the $2.4 \mathrm{GHz}$ WLAN band and $3.5 \mathrm{GHz}$ WiMAX band. Compared to the simulated bandwidth of $2.3-2.54 \mathrm{GHz}$ and 3.51$3.83 \mathrm{GHz}$, the frequency shifts a little and good agreement between the measured and simulated results are achieved. In addition, the simulated and measured gains of the proposed antenna are presented and compared in Figure 9(b). The simulated gains for the lower band and the upper band are from 5.6 to $6.2 \mathrm{dBi}$ and from 6 to $7 \mathrm{dBi}$, respectively. The measured gains are from 5.5 to $6 \mathrm{dBi}$ for the lower band and from 6 to $7.1 \mathrm{dBi}$ for the upper band.

Radiation patterns were simulated and measured at 2.45 and $3.65 \mathrm{GHz}$ in the $E$-plane ( $y z$-plane) and the $H$-plane ( $x z$-plane) as shown in Figure 10. It can be seen that the proposed antenna has stable, symmetric, and boresight radiation patterns at both frequencies of 2.45 and $3.65 \mathrm{GHz}$. At $2.45 \mathrm{GHz}$, the measured $3 \mathrm{~dB}$ beamwidths are $62^{\circ}$ and $116^{\circ}$ in the $E$ - and $H$-planes, respectively. The measured maximum cross-polarization levels are $-38 \mathrm{~dB}$ and $-24 \mathrm{~dB}$ in the $E$ and $H$-planes, respectively. At $3.65 \mathrm{GHz}$, the measured $3 \mathrm{~dB}$ beamwidths in the $E$ - and $H$-planes are $73^{\circ}$ and $102^{\circ}$, respectively. The measured maximum cross-polarization levels are $-38 \mathrm{~dB}$ and $-20 \mathrm{~dB}$ in the $E$ - and $H$-planes, respectively. In addition, the measured front-to-back ratios are around $20 \mathrm{~dB}$ at both frequencies, which is lower than the simulated results of $20 \mathrm{~dB}$ and $24 \mathrm{~dB}$ at 2.45 and $3.65 \mathrm{GHz}$, respectively. The difference may be due to the inaccuracies in the fabrication process.

L-shaped probe is also an effective method for achieving wide bandwidth in patch antennas. The reflection coefficients and gains of the L-probe fed patch antenna with U-slots are depicted in Figure 11 as compared with those of the proposed M-probe fed patch antenna. It can be seen that the bandwidth of the L-probe fed dual-band patch antenna at lower band ( $2.45 \mathrm{GHz}$ band) is comparable with that of the proposed M-probe fed patch antenna. However, the bandwidth at higher band (3.6 GHz band) is narrower than that of the proposed antenna. Besides, as shown in Figure 12, the crosspolarization at higher band is much higher than that in 

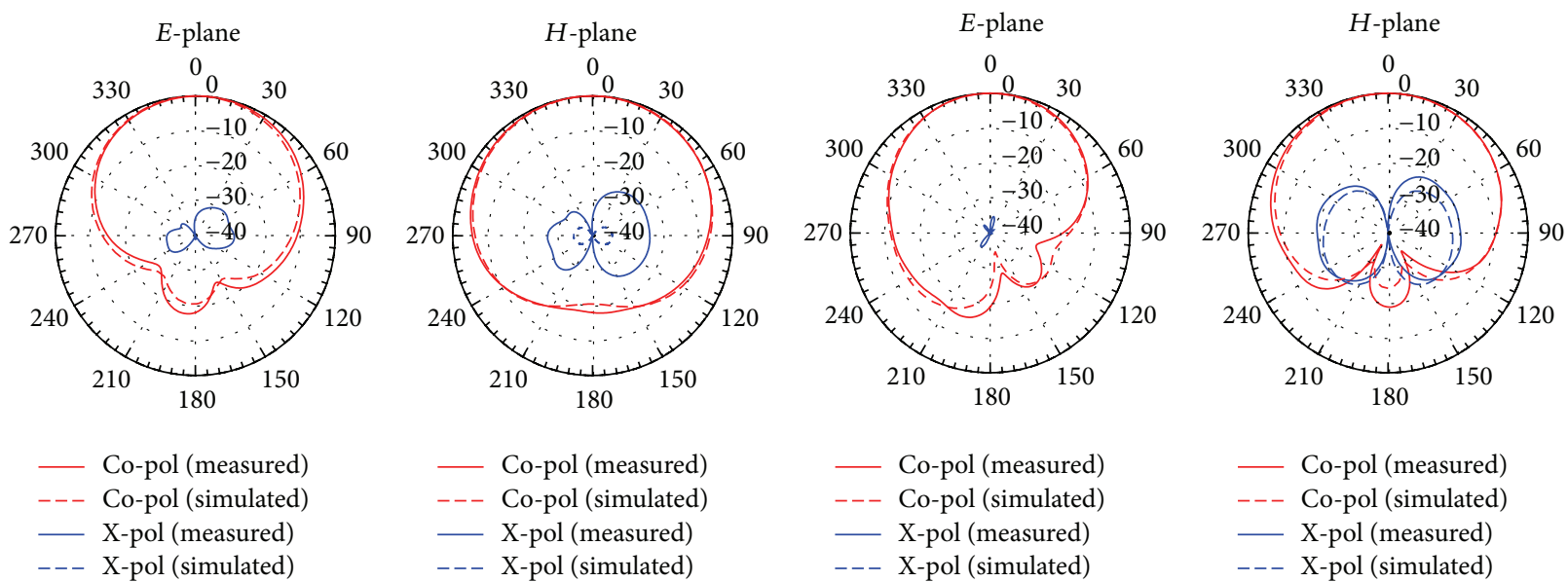

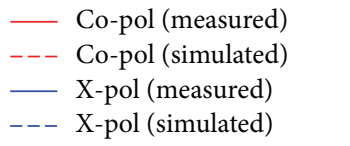

(a)

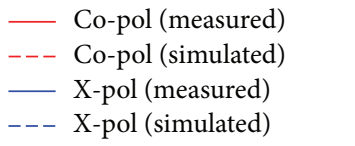

- - X-pol (simulated)

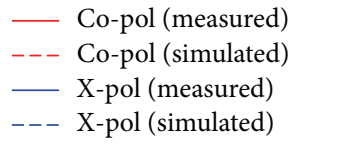

(b)

FIGURE 10: Simulated and measured radiation patterns for the proposed antenna at (a) $2.45 \mathrm{GHz}$ and (b) $3.65 \mathrm{GHz}$.

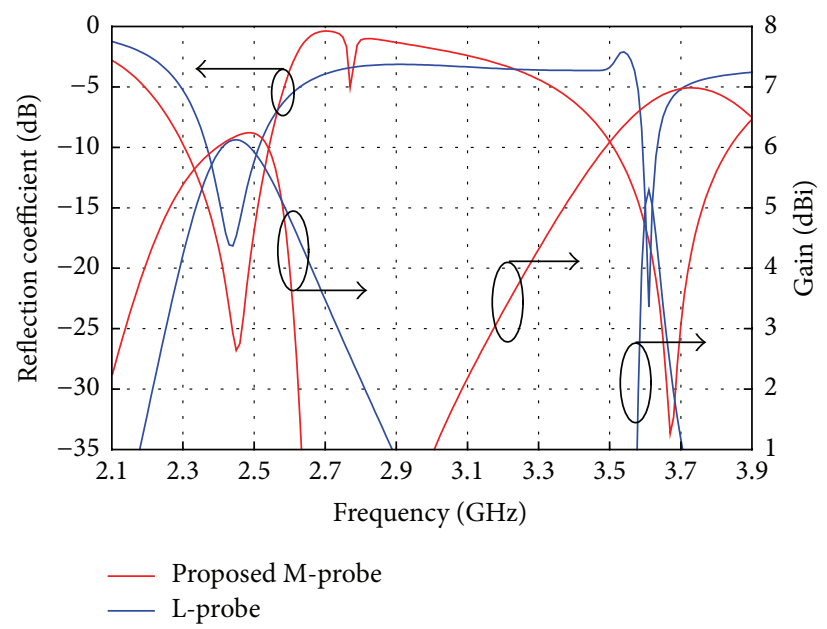

FIGURE 11: Simulated and measured reflection coefficients and gains for the proposed patch antenna comparing with L-probe fed patch antenna.

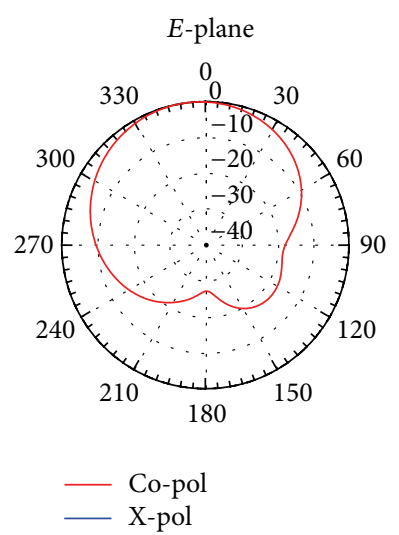

(a)
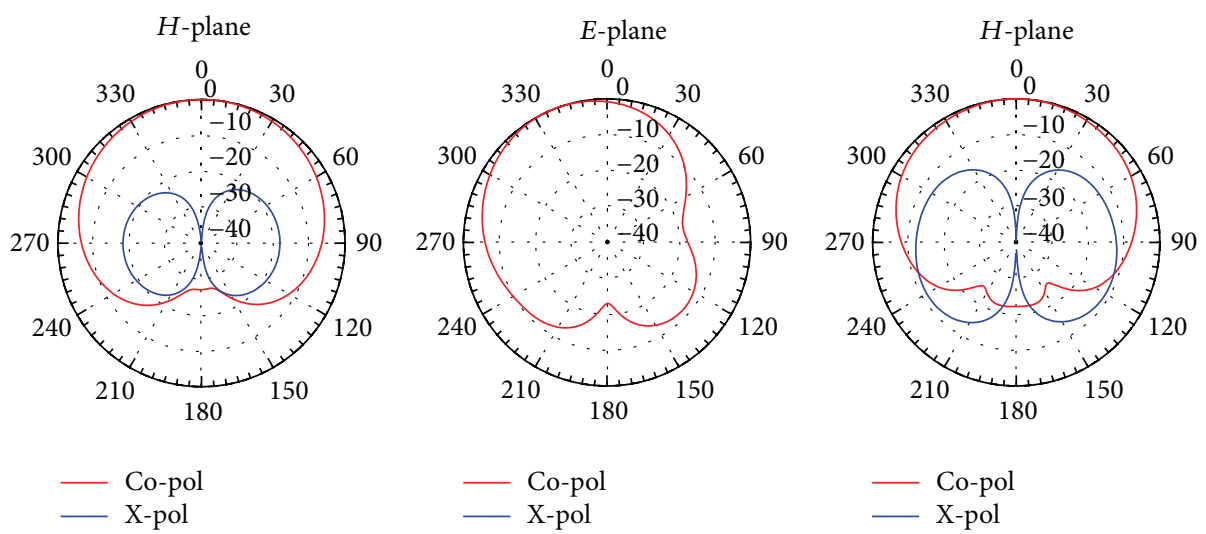

(b)

FIGURE 12: Simulated radiation patterns for the patch antenna fed by L-probe at (a) $2.44 \mathrm{GHz}$ and (b) $3.61 \mathrm{GHz}$. 
the proposed antenna. This is due to the radiation of the asymmetric currents on the L-shaped probe. The results show that the proposed $\mathrm{M}$-probe fed scheme benefit from the wide bandwidth and low cross-polarization at both bands, which makes it as a better candidate for dual-band application than the L-probe patch antenna.

\section{Conclusion}

In this paper, a compact dual-band patch antenna with low cross-polarization levels fed by substrate-integrated Mprobe has been demonstrated. The dual-band characteristic is attributed to the patch with two current paths. The low cross-polarization radiation has been achieved by the proposed SIM-probe fed technique. The antenna exhibits good performance at $2.4 \mathrm{GHz}$ WLAN and $3.5 \mathrm{GHz}$ WiMAX bands. The cross-polarization levels are as low as $-20 \mathrm{~dB}$ within both bands. On the other hand, the substrate-integrated structure makes it convenient to be fabricated by the mature PCB technology and be integrated with RF front-end. Hence, the proposed antenna is useful in modern wireless communications.

\section{Conflict of Interests}

The authors declare that there is no conflict of interests regarding the publication of this paper.

\section{Acknowledgments}

This work is supported by the Natural Science Foundation of Guangdong Province under Grant no. 2015A030310249 and the open program from State Key Laboratory of Millimeter Waves under Grant no. K201612.

\section{References}

[1] M. Samsuzzaman, T. Islam, N. H. Abd Rahman, M. R. I. Faruque, and J. S. Mandeep, "Coplanar waveguide fed compact wide circular-slotted antenna for Wi-Fi/WiMAX applications," International Journal of Antennas and Propagation, vol. 2014, Article ID 982958, 10 pages, 2014.

[2] N. Ortiz, F. Falcone, and M. Sorolla, "Gain improvement of dual band antenna based on complementary rectangular split-ring resonator," ISRN Communications and Networking, vol. 2012, Article ID 951290, 9 pages, 2012.

[3] S. Verma and P. Kumar, "Compact triple-band antenna for WiMAX and WLAN applications," Electronics Letters, vol. 50, no. 7, pp. 484-486, 2014.

[4] H. Zhai, Q. Gao, C. Liang, R. Yu, and S. Liu, "A dualband high-gain base-station antenna for WLAN and WiMAX applications," IEEE Antennas and Wireless Propagation Letters, vol. 13, pp. 876-879, 2014.

[5] S. Shrestha, S. R. Lee, and D.-Y. Choi, "A new fractal-based miniaturized dual band patch antenna for RF energy harvesting," International Journal of Antennas and Propagation, vol. 2014, Article ID 805052, 9 pages, 2014.
[6] L. Sun, M. He, J. Hu, Y. Zhu, and H. Chen, "A butterfly-shaped wideband microstrip patch antenna for wireless communication," International Journal of Antennas and Propagation, vol. 2015, Article ID 328208, 8 pages, 2015.

[7] Y. Li, L. Li, X. Dai, C. Zhu, F. Huo, and G. Dong, "Compact shorted stacked-patch antenna integrated with chip-package based on LTCC technology," International Journal of Antennas and Propagation, vol. 2014, Article ID 235847, 11 pages, 2014.

[8] W. C. Mok, S. H. Wong, K. M. Luk, and K. F. Lee, "Single-Layer single-patch dual-band and triple-band patch antennas," IEEE Transactions on Antennas and Propagation, vol. 61, no. 8, pp. 4341-4344, 2013.

[9] P. Li, K. M. Luk, and K. L. Lau, "A dual-feed dual-band Lprobe patch antenna," IEEE Transactions on Antennas and Propagation, vol. 53, no. 7, pp. 2321-2323, 2005.

[10] Q. Xue, X. Y. Zhang, and C.-H. K. Chin, "A novel differentialfed patch antenna," IEEE Antennas and Wireless Propagation Letters, vol. 5, no. 1, pp. 471-474, 2006.

[11] H. W. Lai and K. M. Luk, "Design and study of wide-band patch antenna fed by meandering probe," IEEE Transactions on Antennas and Propagation, vol. 54, no. 2, pp. 564-571, 2006. 


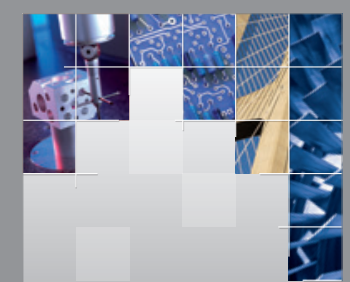

\section{Enfincering}
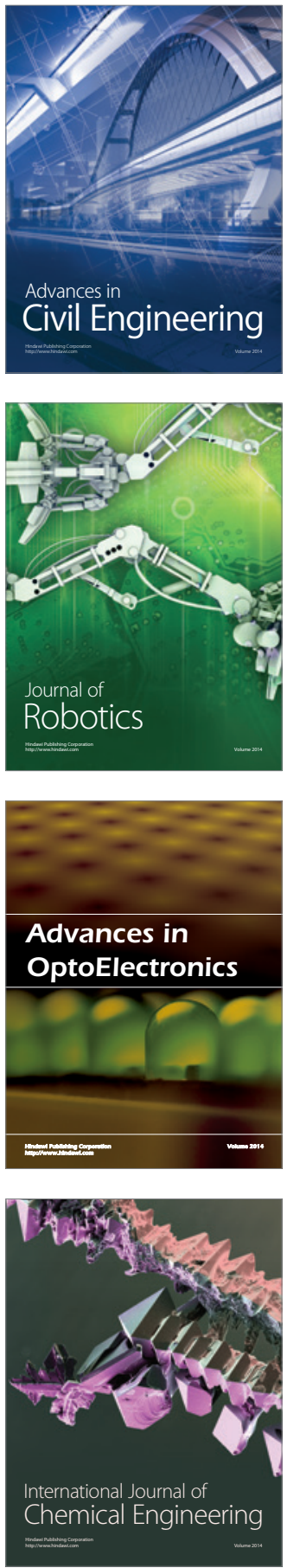

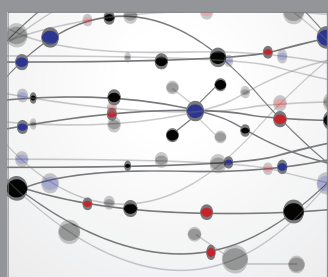

The Scientific World Journal

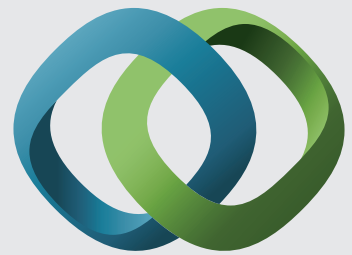

\section{Hindawi}

Submit your manuscripts at

http://www.hindawi.com
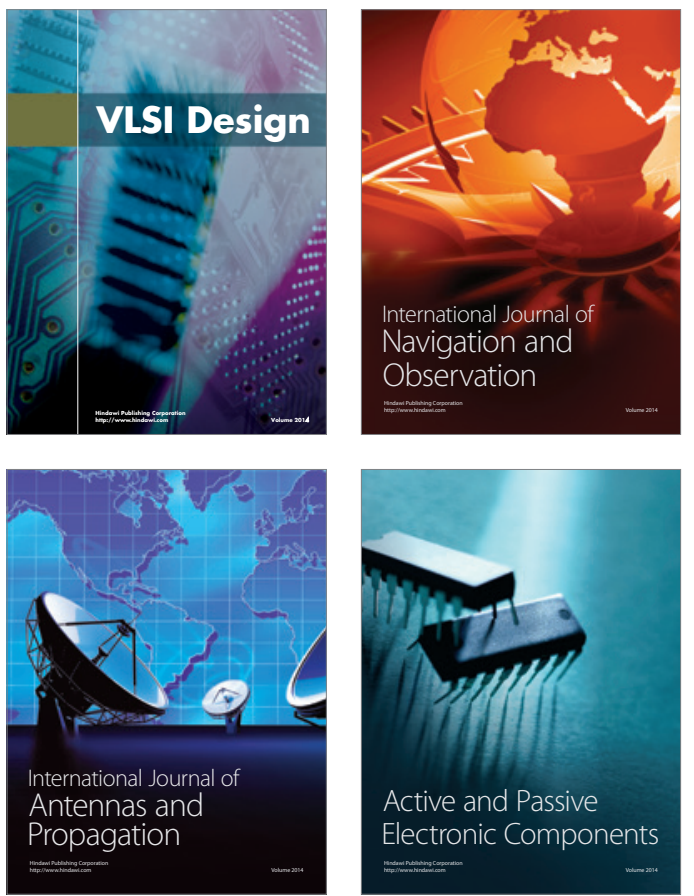
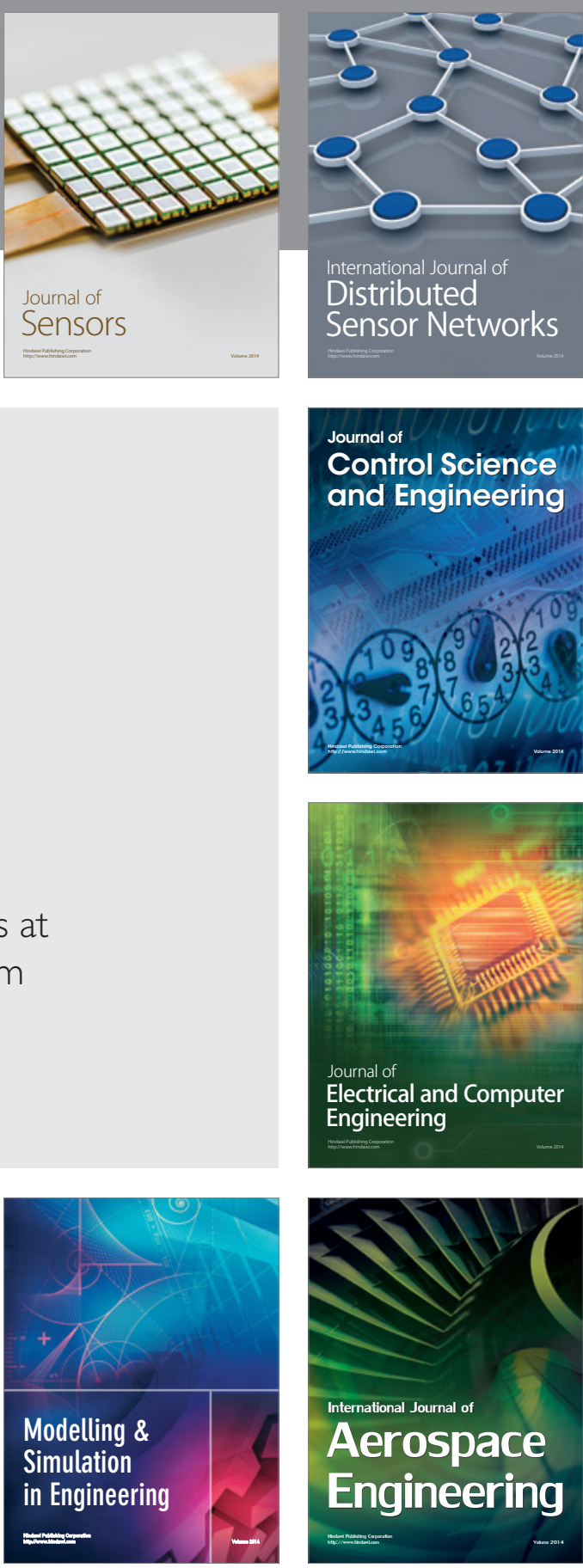

International Journal of

Distributed

Sensor Networks

Journal of

Control Science

and Engineering
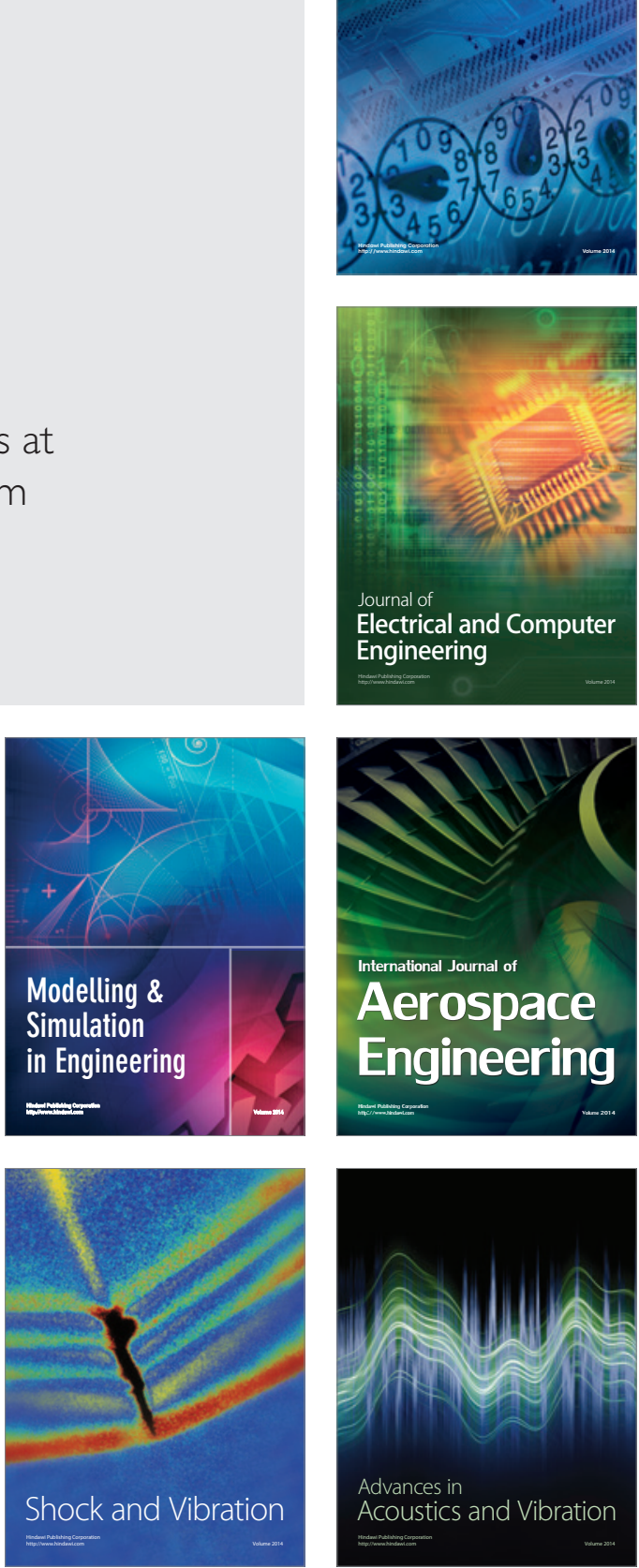